Case Report

\title{
An Uncommon Presentation of Spontaneous Rectus Sheath Hematoma with Acute Kidney Injury due to Obstructive Uropathy and Prerenal Azotemia
}

\author{
Eleni Paschou, ${ }^{1}$ Eleni Gavriilaki, ${ }^{2}$ Asterios Kalaitzoglou, ${ }^{2}$ \\ Maria Mourounoglou, ${ }^{3}$ and Nikolaos Sabanis ${ }^{4}$ \\ ${ }^{1}$ Department of Family Medicine, General Hospital of Pella, 58200 Edessa, Greece \\ ${ }^{2}$ Medical School, Aristotle University of Thessaloniki, 54124 Thessaloniki, Greece \\ ${ }^{3}$ Department of General Surgery, General Hospital of Pella, 58200 Edessa, Greece \\ ${ }^{4}$ Nephrological Department, General Hospital of Pella, 58200 Edessa, Greece
}

Correspondence should be addressed to Eleni Paschou; el_paschou@yahoo.gr

Received 26 May 2014; Accepted 29 June 2014; Published 13 July 2014

Academic Editor: Aristomenis K. Exadaktylos

Copyright (C) 2014 Eleni Paschou et al. This is an open access article distributed under the Creative Commons Attribution License, which permits unrestricted use, distribution, and reproduction in any medium, provided the original work is properly cited.

\begin{abstract}
Rectus Sheath Hematoma (RSH) represents an unusual entity which is characterized by acute abdominal pain and tender palpable abdominal mass usually, among elderly patients receiving anticoagulant therapy. We report the case of an 81-year-old woman admitted to our department due to acute abdominal pain and oligoanuria. The patient had recently been hospitalized due to acute myocardial infarction (AMI) and atrial fibrillation (AF) and received both anticoagulant and antiplatelet therapies. The radiological assessments revealed an extended Rectus Sheath Hematoma and bilateral hydronephrosis. Treatment of the hematoma required cessation of anticoagulants and antiplatelet agents, immobilization, blood and fresh frozen plasma transfusion, and administration of vasopressors. The patient recovered gradually and was discharged home fifteen (15) days later.
\end{abstract}

\section{Introduction}

During the last years, anticoagulant and antiplatelet agents have been extensively used, as a treatment or prophylaxis of several conditions in increased thrombotic risk, such as venous thromboembolism, pulmonary embolism, acute coronary syndromes, atrial fibrillation and stroke. However, the benefits do not always outweigh the risks of antithrombotic therapy, since a number of adverse events have been reported. Rectus Sheath Hematoma (RSH) represents an uncommon complication of anticoagulant therapy that can be misdiagnosed because it mimics other causes of abdominal pain.

Herein, we report an interesting case of an elderly patient with abdominal pain caused by RSH who received conservative treatment in time, avoiding further complications.

\section{Case Report}

An 81-year-old Caucasian female presented to our emergency department with acute abdominal pain and oligoanuria (urinary output $100 \mathrm{~mL} / 8 \mathrm{~h}$ ). Her medical history included a recent hospitalization due to acute myocardial infarction (AMI) and atrial fibrillation (AF), treated with amiodarone intravenous infusion (amiodarone $300 \mathrm{mg}$ bolus iv) and anticoagulant therapy with acenocoumarol and dual antiplatelet treatment (aspirin $100 \mathrm{mg}$ per day; clopidogrel $75 \mathrm{mg}$ per day). During the first hospitalization, she developed amiodarone-induced hepatotoxicity. Therefore, the treatment with acenocoumarol was interrupted and replaced with low molecular weight heparin (LMWH) (nadroparin 5700 antiXA/0.6 mL twice daily) while antiplatelet treatment continued. Eight (8) days after she was discharged 


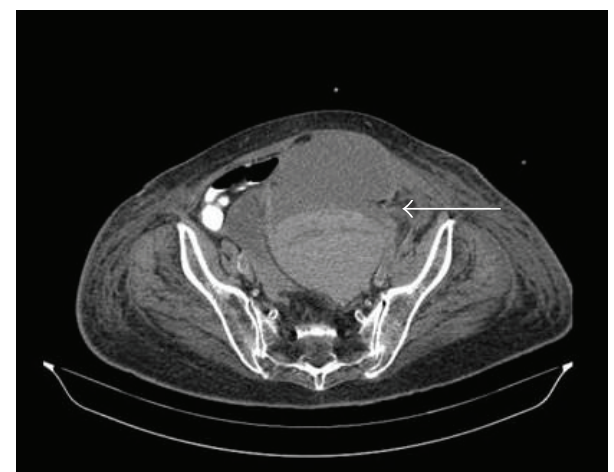

FIGURE 1: Rectus Sheath Hematoma: "hematocrit formation" point.

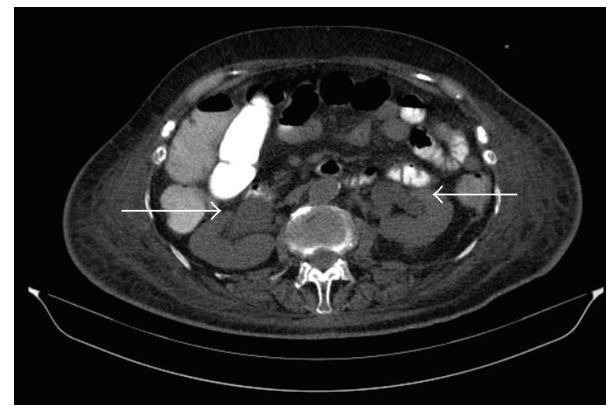

FIGURE 2: Rectus Sheath Hematoma: distension of renal pelvic system bilaterally.

home, she presented in the emergency department hemodynamically unstable (BP: 80/60 mmHg, HR: 115 bpm) with tachypnea and low grade fever. Physical examination demonstrated a painful mass extending to the lower abdomen and upper ecchymosis. Routine laboratory examinations revealed anemia, acute renal failure, hypocalcaemia, and coagulation disturbances (Table 1-Day 1). Urinalysis showed acute tubular necrosis (Specific Gravity 1027, pH 6, WBCs 0-1, RBCs $0-1$, and browncast cylindroids). Both abdominal ultrasonography and abdominopelvic CT scan demonstrated an hematoma at lower abdomen, on the left rectus abdominis muscle extending to the pelvis (dimensions $11.3 \times$ $14.6 \times 10.5 \mathrm{~cm})$, presented with the "hematocrit formation" point (Figure 1). Furthermore, bilateral hydronephrosis was observed due to hematoma's invasive traits. Central venous pressure (CVP) was $3 \mathrm{mmHg}$ and intra-abdominal pressure (IAP), using the intravesicular method, was $21 \mathrm{mmHg}$ (abdominal compartment syndrome (ACS)). Acute kidney injury correlated with acute tubular necrosis and postrenal obstructive uropathy (Figure 2).

Anticoagulant and antiplatelet agents were ceased. On day 1 , in accordance with CVP, intravenous fluids $(0.9 \%$ sodium chloride solution) were infused in order to restore intravascular volume. The patient received two packed red blood cells transfusions, one fresh frozen plasma transfusion and calcium gluconate $(10 \mathrm{~mL}$ calcium gluconate $10 \% / 8 \mathrm{~h}$ ) because of the blood clotting mechanism's disturbances. On day 2, despite normal ranges of CVP, the patient was hemodynamically unstable and was treated with vasopressors (dopamine $10 \mu \mathrm{g} / \mathrm{kg} / \mathrm{min}$ ). The above measures increased blood pressure to $120 \mathrm{mmHg}$ and the urinary output improved $(400 \mathrm{~mL} / 8 \mathrm{~h})$. The patient recovered gradually after fifteen (15) days of bed rest, without any complications, and was discharged hemodynamically stable (BP: 115/80) with normal IAP (7 mmHg), renal and liver function (Table 1Day 15), while she had received four packed red blood cells and six fresh frozen plasma transfusions in total.

\section{Discussion}

RSH is usually a self-limiting entity that potentially can lead to severe complications. Obstructive uropathy [1] and abdominal compartment syndrome [2] are uncommon complications even though $\mathrm{RSH}$ is involved with other rare entities such as hemoperitoneum [3], gross hematuria [4], rectus abdominis myonecrosis [5], ileocecal perforation [6], and small bowel infraction [7].

The mortality rate has been reported at $4 \%$ in general population and up to $25 \%$ in patients under anticoagulant therapy. It is more frequent in female and elderly patients, mainly because of their decreased muscle mass [8].

$\mathrm{RSH}$ is a rare cause of acute abdominal pain presenting with ecchymosis and abdominal wall mass due to rupture of epigastric vessels or arteries. It occurs usually unilateral, although some rare cases of bilateral hematomas have been reported, as complications of kidney transplantation [9] and alcohol liver disease [10]. Symptoms following the appearance of $\mathrm{RSH}$ are mainly nonspecific and include fever, hypovolaemia, nausea, vomiting, and diarrhea. Recognition of clinical signs such as Cullen, Grey-Turner, Carnett (tenderness remains the same or increases with head raising) $[11,12]$, and Fothergill's sign (the abdominal mass in RSH does not cross the midline and, in contrast to an intraperitoneal mass, it remains conspicuous on tensing the abdominal wall musculature by head or leg raising) [13] may be beneficial for diagnostic approach.

The main risk factors for $\mathrm{RSH}$ are anticoagulant therapies, coagulation disorders, previous surgical operations [14], abdominal trauma, increased intra-abdominal pressure (cough, sneezing, strenuous exercise [15, 16], pregnancy [17], and constipation), cardiovascular diseases, and myopathies [18]. Other causes have been also described in case reports, such as acupuncture [19], subcutaneous injection, foley catheterization [20], endometriosis of rectus abdominis, transvaginal follicle aspiration during in vitro fertilisation [21], HCV-related mixed cryoglobulinemia [22], lymphoproliferative disease after renal transplantation [23], and tetanus [24].

The role of ultrasonography and computed tomography is crucial, although computed tomography appears to be the most accurate way of confirming the diagnosis [25].

According to Berná et al. [26] and Osinbowale and Bartholomew [13] RSH can be classified into three categories that can lead to appropriate therapeutic strategies (Table 2).

There have been reported only few cases of RSH complicated with acute kidney injury. The causes in these cases seem to be prerenal, intrarenal, or postrenal. Our patient appeared 
TABLE 1: Routine laboratory examination.

\begin{tabular}{|c|c|c|c|c|c|}
\hline & Day 1 & Day 2 & Day 3 & Day 7 & Day 15 \\
\hline WBC count $\left(\times 10^{3} / \mu \mathrm{L}\right)$ & 12,36 & 13,57 & 13,12 & 9,78 & 7,65 \\
\hline Hemoglobulin (g/dL) & 7,9 & 8,6 & 8,8 & 11 & 11,5 \\
\hline Hematocrit (\%) & 24,2 & 27,7 & 29,8 & 33,5 & 36,2 \\
\hline Platelet count $\left(\times 10^{3} / \mu \mathrm{L}\right)$ & 145 & 157 & 159 & 162 & 154 \\
\hline Serum creatinine (mg/dL) & 2,73 & 2,69 & 2,14 & 1,56 & 1,12 \\
\hline Urea $(\mathrm{mg} / \mathrm{dL})$ & 140 & 114 & 98 & 60 & 43 \\
\hline SGOT (mg/dL) & 226 & 234 & 217 & 85 & 36 \\
\hline SGPT (mg/dL) & 432 & 392 & 366 & 109 & 40 \\
\hline Serum calcium $(\mathrm{mg} / \mathrm{dL})^{*}$ & 6,7 & 6,9 & 7,1 & 7,6 & 8,2 \\
\hline Activated partial thromboplastin time (aPTT) (sec) & 38,7 & 36,7 & 32 & 29,9 & 27,9 \\
\hline Fibrinogen $(\mathrm{g} / \mathrm{L})$ & 1,53 & 1,66 & 2,01 & 2,6 & 2,9 \\
\hline International normalized ratio (INR) & 1,84 & 1,67 & 1,34 & 1,27 & 1,1 \\
\hline
\end{tabular}

* corrected to albumin.

TABLE 2: Berna and Osinbowale RSH classification. Computed tomography severity grades and suggested management strategy, modified and reprinted with permission from Osinbowale and Bartholomew [13].

\begin{tabular}{llll}
\hline Grade & Anatomic extension & Symptoms & Management \\
\hline I & $\begin{array}{l}\text { Intramuscular, unilateral; does } \\
\text { not dissect along fascial planes. }\end{array}$ & $\begin{array}{l}\text { Mild to moderate pain. No drop } \\
\text { in hemoglobin. }\end{array}$ & $\begin{array}{l}\text { Conservative; usually outpatient } \\
\text { follow-up only. }\end{array}$ \\
\hline II & $\begin{array}{l}\text { Bilateral; some dissection } \\
\text { between the muscle and } \\
\text { transversalis fascia; no extension } \\
\text { into the prevesical space. }\end{array}$ & Minor drop in hemoglobin. & $\begin{array}{l}\text { Observation, short hospital stay. } \\
\text { May need transfusion. }\end{array}$ \\
\hline III & $\begin{array}{l}\text { Bilateral, large; dissects between } \\
\text { the transversalis fascia and } \\
\text { muscle into the peritoneum and } \\
\text { prevesical space. }\end{array}$ & $\begin{array}{l}\text { Significant drop in hemoglobin } \\
\text { and hemodynamic instability. }\end{array}$ & $\begin{array}{l}\text { Reversal of anticoagulants and } \\
\text { blood transfusion. Angiographic } \\
\text { interventions may be needed. }\end{array}$ \\
\hline
\end{tabular}

with both prerenal and postrenal causes. Patient's hemodynamic instability caused prolonged renal ischemia which led to acute tubular necrosis while the bilateral obstructive uropathy caused significant raise of intratubular pressure. As a result of obstructive uropathy, renal blood flow decreased further leading to acute kidney injury.

The pathophysiological mechanisms of blood clotting disturbances in this case are complicated and involve uremia, accumulation of $\mathrm{LMWH}$, and anticoagulant therapy. It is well known that uremia in patients with renal insufficiency leads to qualitative platelet abnormalities, mainly caused by $\mathrm{A} 2$ thromboxane reduced production due to abnormal platelet arachidonic acid metabolism [27]. In these patients, heparin levels should be reduced, especially when creatinine clearance is less than $40 \mathrm{~mL} / \mathrm{min}$ [28], in order to prevent complications. The remarkable points in our case report were that the patient had also amiodarone-induced hepatotoxicity and hypocalcaemia causing further disturbances of blood clotting mechanism [29].

RSH management is mainly supportive, including immobilization, cessation of anticoagulation therapy, and transfusions. Angioembolization may be necessary [30] especially for RSHs related to LMWH [31] and surgical intervention should be reserved for cases with hemodynamic instability which resist in conventional treatment [32].

\section{Conclusions}

RSH should be in mind of physicians during differential diagnosis of acute abdominal pain, especially in elderly patients receiving anticoagulants. The causal nature remains unclear since the underlying pathophysiological pathways are complicated. Early recognition can be of great importance for patients' recovery, preventing from severe complications. Management is usually supportive although surgical intervention in some patients should be considered.

\section{Conflict of Interests}

The authors declare that there is no conflict of interests regarding the publication of this paper.

\section{References}

[1] J. Toyonaga, K. Tsuruya, K. Masutani et al., "Hemorrhagic shock and obstructive uropathy due to a large rectus sheath hematoma in a patient on anticoagulant therapy," Internal Medicine, vol. 48, no. 24, pp. 2119-2122, 2009.

[2] S. F. Jafferbhoy, Q. Rustum, and M. H. Shiwani, "Abdominal compartment syndrome-a fatal complication from a rectus sheath haematoma," BMJ Case Reports, 2012. 
[3] O. Balafa, S. Koundouris, M. Mitsis, and K. C. Siamopoulos, "An unusual case of hemoperitoneum: spontaneous rectus sheath hematoma," Peritoneal Dialysis International, vol. 34, no. 1, pp. 134-135, 2014.

[4] O. Sandoval and T. Kinkead, "Spontaneous rectus sheath hematoma: an unusual cause of gross hematuria," Urology, vol. 82, no. 6, pp. e35-e36, 2013.

[5] L. C. Patten, S. S. Awad, D. H. Berger, and S. P. Fagan, "Rectus abdominus myonecrosis: an unrecognized complication of rectus sheath hematoma," Journal of Trauma, vol. 59, no. 2, pp. 475-477, 2005.

[6] A. Tsiouris, A. Falvo, J. H. Patton, and A. C. Sisley, "Rectus sheath hematoma causing ileocecal perforation," American Surgeon, vol. 78, no. 9, pp. 1009-1010, 2012.

[7] R. A. Dineen, N. R. Lewis, and N. Altaf, "Small bowel infarction complicating rectus sheath haematoma in an anticoagulated patient," Medical Science Monitor, vol. 11, no. 10, pp. CS57-CS59, 2005.

[8] W. B. Cherry and P. S. Mueller, "Rectus sheath hematoma: review of 126 cases at a single institution," Medicine, vol. 85, no. 2, pp. 105-110, 2006.

[9] B. Feizzadeh Kerigh and G. Maddah, "Bilateral rectus sheath hematoma in kidney transplant patient: case study and literature review," Nephro-Urology Monthly, vol. 5, no. 4, pp. 921-923, 2013.

[10] J. G. Docherty and A. L. Herrick, "Bilateral rectus sheath haematoma complicating alcoholic liver disease," British Journal of Clinical Practice, vol. 45, no. 4, article 289, 1991.

[11] H. Thomson and D. M. A. Francis, "Abdominal-wall tenderness: a useful sign in the acute abdomen," The Lancet, vol. 2, no. 8047, pp. 1053-1054, 1977.

[12] D. W. R. Gray, J. M. Dixon, G. Seabrook, and J. Collin, "Is abdominal wall tenderness a useful sign in the diagnosis of non-specific abdominal pain?" Annals of the Royal College of Surgeons of England, vol. 70, no. 4, pp. 233-234, 1988.

[13] O. Osinbowale and J. R. Bartholomew, "Rectus sheath hematoma," Vascular Medicine, vol. 13, no. 4, pp. 275-279, 2008.

[14] F. Procacciante, G. Diamantini, D. Paolelli, and P. Picozzi, "Rectus sheath haematoma as an early complication of laparoscopic hemicolectomy: a case report and review of the literature," Chirurgia Italiana, vol. 61, no. 4, pp. 481-483, 2009.

[15] Y. Choi and D. Lee, "A case of rectus sheath hematoma caused by yoga exercise," The American Journal of Emergency Medicine, vol. 27, no. 7, pp. 899.e1-899.e2, 2009.

[16] L. Barna, I. Toth, E. Kovacs, and E. Krizso, "Rectus sheath haematoma following exercise testing: a case report," Journal of Medical Case Reports, vol. 3, article 9000, 2009.

[17] M. C. Tolcher, J. F. Nitsche, K. W. Arendt, and C. H. Rose, "Spontaneous rectus sheath hematoma pregnancy: case report and review of the literature," Obstetrical and Gynecological Survey, vol. 65, no. 8, pp. 517-522, 2010.

[18] M. Yamagishi, S. Tajima, A. Suetake et al., "Dermatomyositis with hemorrhagic myositis," Rheumatology International, vol. 29, no. 11, pp. 1363-1366, 2009.

[19] S. P. Cheng and C. L. Liu, "Rectus sheath hematoma after acupuncture," Journal of Emergency Medicine, vol. 29, no. 1, pp. 101-102, 2005.

[20] Y. H. Choi, D. H. Lee, S. Y. Yun, and J. H. Lee, "A case of rectus sheath hematoma due to Foley catheterization after acute urinary retention," The American Journal of Emergency Medicine, vol. 30, no. 5, pp. 837.e3-837.e4,, 2012.
[21] J. G. Wang, M. J. Huchko, S. Kavic, and M. V. Sauer, "Rectus sheath hematoma after transvaginal follicle aspiration: a rare complication of in vitro fertilization," Fertility and Sterility, vol. 84, no. 1, article 217, 2005.

[22] C. M. Moschella, I. Palmieri, P. Bartolucci, M. Assenza, A. Maiuolo, and C. Modini, "Spontaneous rectus sheath haematoma in HCV mixed cryoglobulinemia requiring emergency treatment (case report)," Il Giornale di Chirurgia, vol. 23, no. 8-9, pp. 331-333, 2002.

[23] A. Franco, L. Jiménez, C. Muñoz, M. Chulia, P. Marco, and E. Muñoz, "Hematoma of the anterior rectus abdominis muscle as the first manifestation of lymphoproliferative disease after renal transplantation," Nefrologia, vol. 20, no. 6, pp. 559-562, 2000.

[24] G. M. Suhr and A. E. Green Jr., "Rectus abdominis sheath hematoma as a complication of tetanus. Diagnosis by computed tomography scanning," Clinical Imaging, vol. 13, no. 1, pp. 82-86, 1989.

[25] A. Moreno Gallego, J. L. Aguayo, B. Flores et al., "Ultrasonography and computed tomography reduce unnecessary surgery in abdominal rectus sheath haematoma," British Journal of Surgery, vol. 84, no. 9, pp. 1295-1297, 1997.

[26] J. D. Berná, V. Garcia-Medina, J. Guirao, and J. Garcia-Medina, "Rectus sheath hematoma: diagnostic classification by CT," Abdominal Imaging, vol. 21, no. 1, pp. 62-64, 1996.

[27] G. Remuzzi, A. Benigni, P. Dodesini et al., "Reduced platelet thromboxane formation in uremia. Evidence for a functional cyclooxygenase defect," Journal of Clinical Investigation, vol. 71, no. 3, pp. 762-768, 1983.

[28] P. J. Denard, J. C. Fetter, and L. R. Zacharski, "Rectus sheath hematoma complicating low-molecular weight heparin therapy," International Journal of Laboratory Hematology, vol. 29, no. 3, pp. 190-194, 2007.

[29] Y. Caraco, D. Raveh, M. Flugelman, and I. Raz, "Enhanced anticoagulant effect of acenocoumarol induced by amiodarone coadministration," Israel Journal of Medical Sciences, vol. 24, no. 11, pp. 688-689, 1988.

[30] G. Kasotakis, "Retroperitoneal and rectus sheath hematomas," Surgical Clinics of North America, vol. 94, no. 1, pp. 71-76, 2014.

[31] A. Smithson, J. Ruiz, R. Perello, M. Valverde, J. Ramos, and L. Garzo, "Diagnostic and management of spontaneous rectus sheath hematoma," European Journal of Internal Medicine, vol. 24, no. 6, pp. 579-582, 2013.

[32] A. Buffone, G. Basile, M. Costanzo et al., "Management of patients with rectus sheath hematoma: personal experience," Journal of the Formosan Medical Association, 2013. 


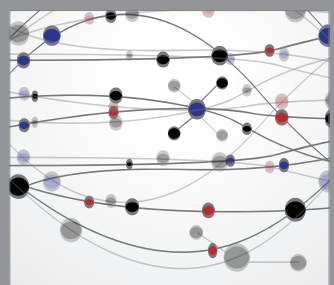

The Scientific World Journal
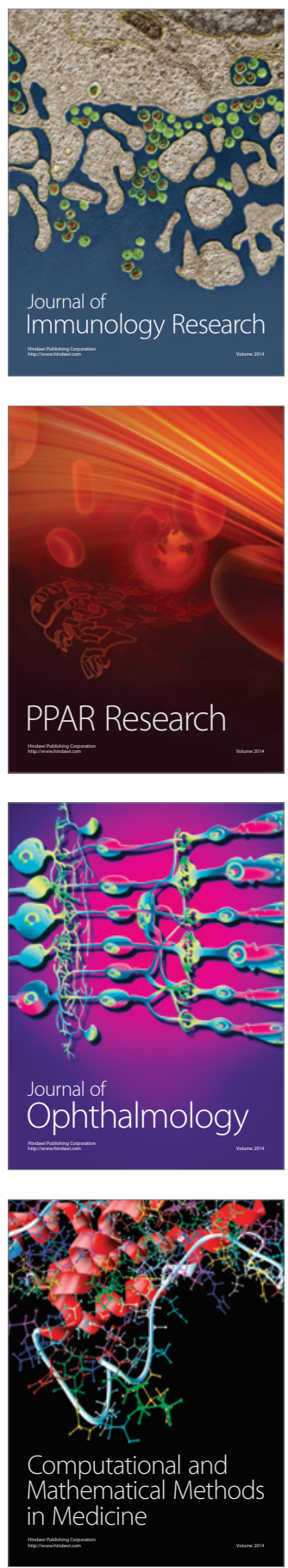

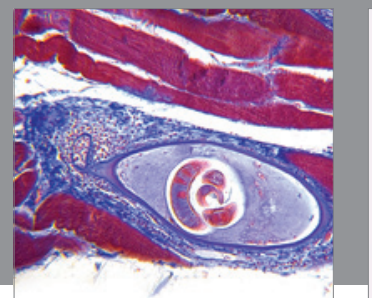

Gastroenterology

Research and Practice
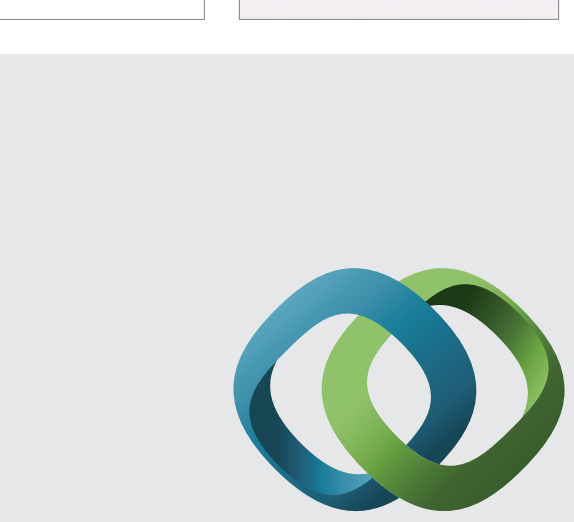

\section{Hindawi}

Submit your manuscripts at

http://www.hindawi.com
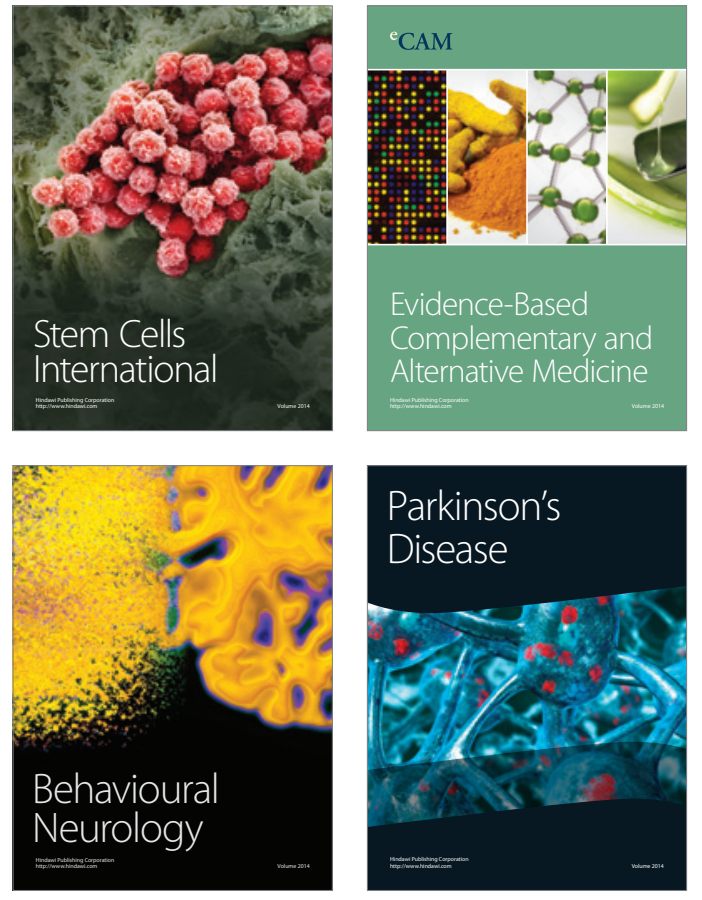
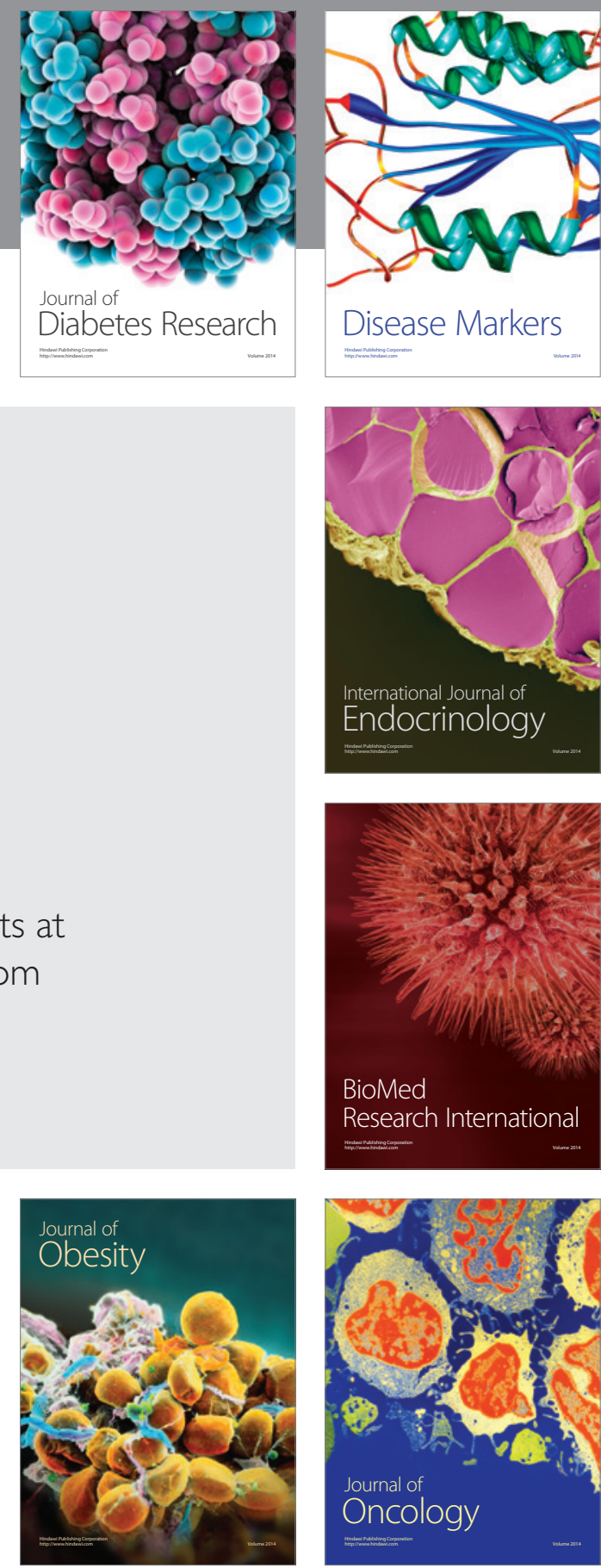

Disease Markers
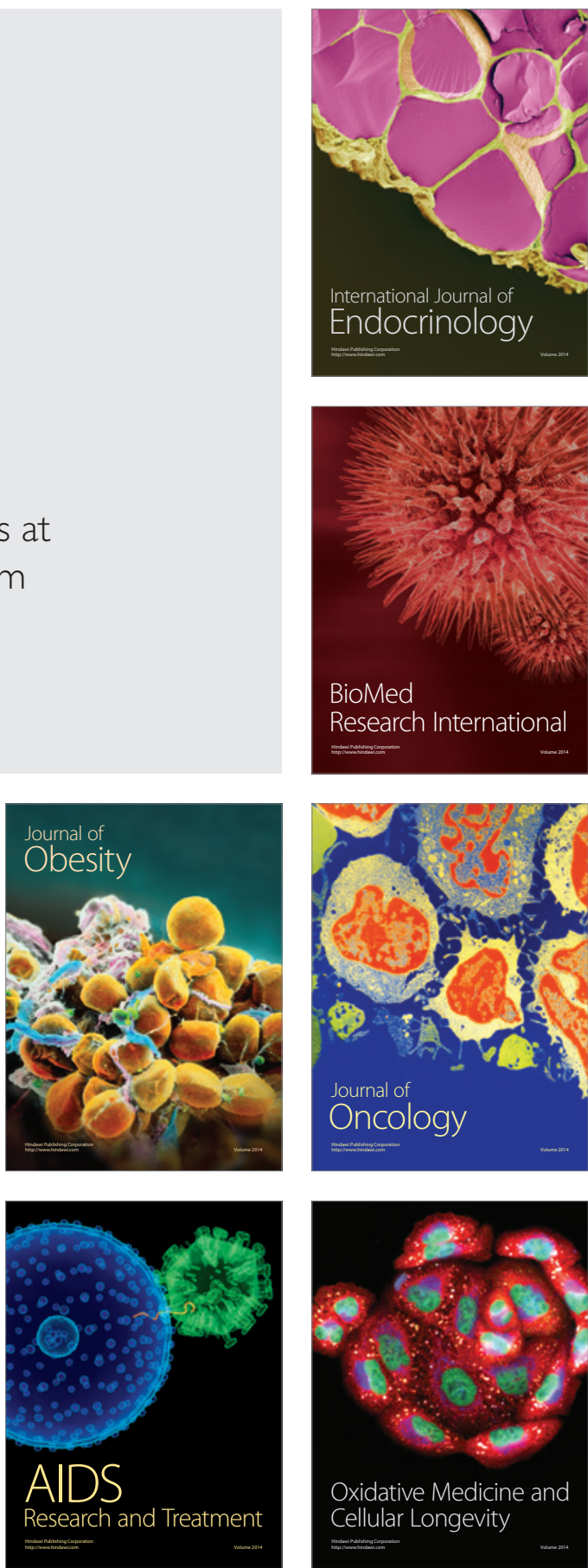